\title{
International normalized ratio for the guidance of warfarin treatment in elderly patients after cardiac valve replacement
}

\author{
QING-HUA MA and JIAN-HAI FANG \\ Department of Cardiology, Linyi Central Hospital, Linyi, Shandong 276400, P.R. China
}

Received April 11, 2018; Accepted September 13, 2018

DOI: $10.3892 /$ etm.2018.7078

\begin{abstract}
Thus far, the target value for international normalized ratio (INR) has remained to be determined. The current study aimed to further explore the INR value of the anti-coagulation drug warfarin after cardiac valve replacement. The clinical data of 213 patients who underwent cardiac valve replacement at Linyi Central Hospital (Linyi, China) between January 2010 and May 2013 were retrospectively analyzed. The warfarin dosage, prothrombin time (PT) and INR were compared among patients with hemorrhage or embolism, and those with no complications. A total of 31 cases (14.6\%) developed adverse reactions and complications during the medication period, including 21 cases with hemorrhage (9.9\%, hemorrhage group) and 10 cases with embolism $(4.7 \%$, embolism group), while 182 patients did not $(85.4 \%$, normal group). The average dosage of warfarin was $2.0 \pm 0.6,3.1 \pm 0.7$ and $1.7 \pm 0.6 \mathrm{mg} /$ day in the normal, hemorrhage and embolism groups, respectively. The dosage of warfarin, the PT and the INR in the hemorrhage group were all significantly greater than those in the normal group and the embolism group (all $\mathrm{P}<0.05)$. INR monitoring is recommended to ensure the safety of the anti-coagulant drug warfarin, but further study is still required to determine a reasonable target INR value.
\end{abstract}

\section{Introduction}

Cardiac valve disease is basically an abnormal heart valve structure caused by rheumatic fever, which leads to a disorder of cardiac hemodynamics and impairs the quality of life of affected patients as well as posing a threat to their lives (1-3). Artificial cardiac valve replacement has effectively improved the life quality of patients and has an important role in the treatment of advanced cardiac valve disease (4). Chikwe et al (5) determined, in a long-term follow-up study,

Correspondence to: Dr Jian-Hai Fang, Department of Cardiology, Linyi Central Hospital, 17 Jiankang Road, Linyi, Shandong 276400, P.R. China

E-mail: jianhaifang9o6t@163.com

Key words: cardiac valve replacement, warfarin, prothrombin time, international normalized ratio, complication that the mean follow-up time was 10.8 years, and the 15-year survival rate following biological and mechanical valve replacement was as high as 57.5 and $59.9 \%$, respectively. An estimated 100,000 patients worldwide undergo cardiac valve replacement due to diseases including rheumatic heart valves and degenerative valves (6). However, patients are required to adhere to anti-coagulant therapy after replacement.

Warfarin effectively inhibits the synthesis of vitamin $\mathrm{K}$ cyclase, which is the most commonly used as anti-coagulant drug for patients after cardiac valve replacement $(7,8)$. A study has indicated that after treatment with warfarin, the synthesis of coagulation factors was effectively inhibited by $>40 \%$ (9). However, excessive or insufficient anti-coagulant effects may cause severe clinical symptoms. The prothrombin time (PT) and international normalized ratio (INR) as preferable clinical indicators of anti-coagulant effects are able to reflect the degree of blood agglutination in patients, providing a basis for clinicians to propose treatment plans for patients. However, the dosage of warfarin and the optimal INR value after cardiac valve replacement in the elderly patients have remained elusive, which was therefore investigated in the present study.

\section{Materials and methods}

Patients. In the present study, 213 patients who received anti-coagulation treatment with warfarin after cardiac valve replacement at Linyi Central Hospital (Linyi, China) between January 2010 and May 2013 and met the inclusion criteria were selected as research subjects and retrospectively analyzed. Of these patients, 70 were males and 143 were females with an age ranging from 57 to 73 years and a mean age of $65.7 \pm 6.4$ years. The cohort included 187 patients with rheumatic heart disease, 13 with infective endocarditis and 13 with congenital cardiomyopathy. Pre-operative color Doppler ultrasound was used to classify cardiac function.

The inclusion criteria were as follows: Course of disease, $\geq 6$ months; no drug therapy, radiotherapy or chemotherapy within 3 months; the complete clinical information was available; and the warfarin anti-coagulation and monitoring strategy were in line with the conventional requirements (10). The exclusion criteria were as follows: Autism, or a memory or hearing impairment; patients with a respiratory system disease, liver or kidney dysfunction, or diabetes; a blood transfusion was not performed 1 month prior to admission; an inherited genetic disease; allergy to warfarin. 
Warfarin anti-coagulant and monitoring routine were as follows: Warfarin was applied for anti-coagulant treatment at $48 \mathrm{~h}$ after surgery. The initial dosage was 3-5 mg/day. After $24 \mathrm{~h}$, 3-5 $\mathrm{ml}$ peripheral blood was collected in an EDTA anti-coagulant tube and sent to the laboratory for PT and INR detection. The dosage of warfarin was adjusted according to the PT/INR index (10). Within the first two weeks after the surgery, PT and INR were examined daily. After the patient's index was stable, monitoring was reduced to once a week and then to once a month after discharge. The frequency of monitoring was determined according to the patient's condition. Patients' complications and adverse reactions, as well as PT and INR values were recorded by querying patients' electronic medical records.

Extraction of patient information. The clinical data of the patients were extracted from the database, including gender, age, type of surgery, body mass index, education level, smoking and drinking habits, and area of residence. Baseline laboratory parameters included white blood cell count $(\mu \mathrm{g} / \mathrm{l})$, platelets $(\mu \mathrm{g} / \mathrm{l})$, cardiac troponin $\mathrm{I}(\mu \mathrm{g} / \mathrm{l})$, creatine kinase $(\mathrm{CK}$, $\mu \mathrm{g} / \mathrm{l}), \mathrm{CK}-\mathrm{muscle} /$ brain $(\mathrm{MB} ; \mu \mathrm{g} / \mathrm{l})$, lactate dehydrogenase $(\mu \mathrm{g} / 1)$, hydroxybutyrate dehydrogenase $(\mu \mathrm{g} / 1)$, C-reactive protein $(\mathrm{mg} / \mathrm{l})$ and aspartate transaminase $(\mu \mathrm{g} / \mathrm{l})$. Changes in INR and PT, the adjustment of the dosage of warfarin and end-of-follow-up events (bleeding, embolism and associated intervention measures), as well as the above indexes were extracted from the hospital's electronic medical record system and the outpatient electronic system.

Grouping. Patients were grouped according to warfarin-associated adverse reactions: The normal group comprised patients with no symptoms and complications, while those with hemorrhage, including hematuria, epistaxis and gastrointestinal hemorrhage, were assigned to the hemorrhage group and those with embolism-associated symptoms, including cerebral infarction and lower limb arterial infarction, were assigned to the embolism group.

Observation indexes. The primary observation indexes of the present study were the differences in PT, INR and warfarin dosage among the normal, hemorrhage and embolism groups. This data was normally distributed, thus the $95 \%$ confidence interval was calculated to evaluate the safety range of PT and INR in elderly patients of the normal group.

Statistical analysis. SPSS version 20.0 software (IBM Corp., Armonk, NY, USA) was used for statistical analysis of all of the data collected in the present study. The measurement data were expressed as the mean \pm standard deviation. One-way analysis of variance was used for comparison among multiple groups, followed by the least-significant differences test for comparison between pairs of groups. The count data were expressed as $\mathrm{n}(\%)$ and compared between groups using the chi-squared test. $\mathrm{P}<0.05$ was considered to indicate a statistically significant difference.

\section{Results}

Clinical characteristics. Significant differences in the cTnI levels were identified among the three groups, of which the embolism group was significantly greater than the hemorrhage and the normal groups; no significant difference was identified between the hemorrhage group and the normal group. No significant differences were identified in other indicators (Table I).

Adverse events. All of the 213 patients were followed up after cardiac valve replacement. A total of 31 patients (14.6\%) experienced adverse reactions and complications, including 21 patients $(9.9 \%)$ with hemorrhage, 10 patients $(4.7 \%)$ with embolism, while the remaining 182 patients $(85.4 \%)$ had no hemorrhage or embolism (Table II).

Comparison of warfarin dosage, and the PT and INR between the patient groups. Significant differences in the warfarin dosage $(\mathrm{F}=27.780, \mathrm{P}<0.001)$, $\mathrm{PT}(\mathrm{F}=45.496, \mathrm{P}<0.001)$ and INR $(\mathrm{F}=16.644, \mathrm{P}<0.001)$ were identified among the three groups after 6 months. The post-hoc test indicated that in the hemorrhage group, the warfarin dosage $(3.1 \pm 0.7 \mathrm{mg} /$ day $)$, PT $(24.6 \pm 2.7 \mathrm{sec})$ and INR $(2.6 \pm 0.7)$ after 6 months were significantly different from those in the normal group (warfarin dosage, $2.1 \pm 0.5 \mathrm{mg} /$ day; PT, 19.4 $\pm 3.1 \mathrm{sec}$ and INR, 1.9 \pm 0.6 ) and the embolism group (warfarin dosage, $1.7 \pm 0.6 \mathrm{mg} /$ day; PT, 13.4 $\pm 1.8 \mathrm{sec}$ and INR 1.5 \pm 0.7 ; all $\mathrm{P}<0.001$; Figs. 1-3). After 6 months, the warfarin dosage $(\mathrm{P}<0.05)$, PT $(\mathrm{P}<0.001)$ and INR $(\mathrm{P}<0.05)$ of the normal group were all significantly higher compared with those of the embolism group.

\section{Discussion}

Cardiac valve replacement is one of the most effective methods for the treatment of mid- to late-stage cardiac valvular diseases. Over the past half century, the number of patients receiving cardiac valve replacement was estimated to be 100,000 per annum worldwide. In China, the cardiac valve replacements account for $30 \%$ of those performed worldwide (11). Rheumatic heart disease is one of the most common types of heart disease, the major causative factor of which is the valve damage caused by inflammation, which leads to problems in the process of transfusion of blood in the patient's heart, including ventricular hypertrophy and dyspnea, while the severe form of the disease may pose a threat to the life of affected patients $(12,13)$. However, the replacement of a cardiac valve is not completely risk-free, and its biggest drawback is that patients require long-term or permanent use of blood anti-coagulants to prevent the occurrence of thromboembolism.

Warfarin as the most widely used clinical anti-coagulant drug, with the mechanism of action being the impairment of the blood coagulation system by inhibiting coagulation factors (including types II, VII, IX and X) synthesized by vitamin $\mathrm{K}$ in the liver. Due to its relatively low cost compared with that of other drugs, its use may reduce the economic burden of patients $(14,15)$. However, the level of warfarin required to achieve a pharmaceutical effect is close to the toxic dose, and ethnic and regional differences with this regard are huge, which requires strict control of the dosage of this drug. In addition, insufficient blood coagulation, thromboembolism and excessive bleeding are likely to occur. Therefore, patients need to be monitored closely for a long time to determine if their condition is stable. At present, patients undergoing 
Table I. Characteristics of the patients.

\begin{tabular}{|c|c|c|c|c|c|}
\hline Parameter & Normal group & Embolism group & Hemorrhage group & $\mathrm{F} / \chi^{2}$ & $\mathrm{P}$ \\
\hline Gender & & & & 3.004 & 0.223 \\
\hline Male & 64 & 2 & 4 & & \\
\hline Female & 118 & 8 & 17 & & \\
\hline Age (years) & & & & 3.045 & 0.218 \\
\hline$>60$ & 139 & 9 & 19 & & \\
\hline$\leq 60$ & 43 & 1 & 2 & & \\
\hline Body mass index $\left(\mathrm{kg} / \mathrm{m}^{2}\right)$ & $26.7 \pm 2.5$ & $25.4 \pm 2.8$ & $27.2 \pm 1.9$ & 1.978 & 0.141 \\
\hline Degree of education & & & & 2.233 & 0.327 \\
\hline$<$ Senior high school & 154 & 7 & 16 & & \\
\hline$\geq$ Senior high school & 28 & 3 & 5 & & \\
\hline Smoking & & & & 1.606 & 0.448 \\
\hline Yes & 122 & 8 & 18 & & \\
\hline No & 60 & 2 & 3 & & \\
\hline Intemperance & & & & 3.159 & 0.206 \\
\hline Yes & 43 & 4 & 8 & & \\
\hline No & 139 & 6 & 13 & & \\
\hline Place of residence & & & & 2.431 & 0.296 \\
\hline Countryside & 102 & 7 & 15 & & \\
\hline City & 80 & 3 & 6 & & \\
\hline Cardiac functional grading & & & & 4.849 & 0.303 \\
\hline II & 77 & 2 & 5 & & \\
\hline III & 60 & 4 & 8 & & \\
\hline IV & 45 & 4 & 8 & & \\
\hline Valve replacement & & & & 5.829 & 0.212 \\
\hline Aortic valve replacement & 53 & 3 & 5 & & \\
\hline Mitral valve replacement & 93 & 3 & 8 & & \\
\hline Aortic valve + mitral valve replacement & 36 & 4 & 8 & & \\
\hline WBC $\left(4.0-10.0 \times 10^{9} / 1\right)$ & $5.58 \pm 1.32$ & $5.62 \pm 1.48$ & $5.54 \pm 1.68$ & 0.013 & 0.987 \\
\hline PLT $\left(100-300 \times 10^{9} / 1\right)$ & $165.15 \pm 45.25$ & $157.35 \pm 41.73$ & $157.37 \pm 48.95$ & 0.139 & 0.870 \\
\hline $\operatorname{cTnI}(0-0.3 \mu \mathrm{g} / \mathrm{l})$ & $2.68 \pm 1.17$ & $3.49 \pm 0.15$ & $3.29 \pm 0.42$ & 5.145 & 0.007 \\
\hline CK (8-60 $\mu \mathrm{g} / \mathrm{l})$ & $53.45 \pm 14.63$ & $53.76 \pm 7.12$ & $56.70 \pm 20.99$ & 0.435 & 0.648 \\
\hline CK-MB $(0-24 \mu \mathrm{g} / \mathrm{l})$ & $6.09 \pm 3.39$ & $4.84 \pm 0.82$ & $6.02 \pm 0.45$ & 0.744 & 0.476 \\
\hline LDH $(109-245 \mu \mathrm{g} / \mathrm{l})$ & $295.41 \pm 69.89$ & $267.72 \pm 11.07$ & $301.87 \pm 41.57$ & 0.965 & 0.383 \\
\hline
\end{tabular}

Values are expressed as $\mathrm{n}(\%)$ or the mean \pm standard deviation. BMI, body mass index; WBC, white blood count; PLT, platelets; cTnI, cardiac troponin I; CK, creatine kinase; MB, muscle/brain; LDH, lactate dehydrogenase; HBDH, hydroxybutyrate dehydrogenase; CRP, C-reactive protein; AST, aspartate transaminase.

cardiac valve replacement are mainly assessed using their PT and INR values as indicators. PT is a very important index reflecting liver synthesis function, reserve function, lesion severity and prognosis (16). INR refers to the ratio of the patient's prothrombin time to the normal prothrombin time, which is an important criterion for judging the dosage of oral anticoagulant drugs (17).

In the present study, the PT and INR were measured in 213 patients who received cardiac valve replacement and subsequently took warfarin. Post-operative adverse events and complications occurring during the follow-up of the patients were recorded and statistically analyzed. It was identified that the percentage of patients with adverse events of hemorrhage was as high as $9.9 \%$, which was slightly higher than the domestic statistics of $0.8-9.2 \%$ (18). This may be because it is difficult to achieve proper anticoagulant strength with self-medication because, as demonstrated by Jiang et al (19), the majority of patients undergoing heart valve replacements are elderly, possess a low educational level and lack of professional knowledge. While PT detection may exhibit differences in different laboratories, leading to a lack of comparability, INR is able to effectively and accurately determine the anti-coagulant effect in patients. At present, there is a certain controversy regarding the normal 
Table II. Adverse events in the different group and their management.

\begin{tabular}{|c|c|c|c|c|}
\hline Group/adverse effect & Cases $(n=213)$ & $\mathrm{PT}(\mathrm{sec})$ & INR & Measure of intervention \\
\hline \multicolumn{5}{|l|}{ Normal control $(\mathrm{n}=182)$} \\
\hline None & $182(85.45)$ & $19.54(14.83-24.94)$ & $2.05(1.28-2.77)$ & None \\
\hline \multicolumn{5}{|l|}{ Hemorrhage group $(n=10)$} \\
\hline Cerebral infarction & $6(2.82)$ & $13.78(11.86-15.62)$ & $1.68(1.07-1.46)$ & $\begin{array}{l}\text { Dosage of warfarin was increased } \\
\text { over time }\end{array}$ \\
\hline Lower limb artery infarction & $4(1.88)$ & $13.75(12.13-15.28)$ & $1.27(1.03-1.43)$ & $\begin{array}{l}\text { Dosage of warfarin was increased } \\
\text { over time }\end{array}$ \\
\hline \multicolumn{5}{|l|}{ Embolism group $(\mathrm{n}=21)$} \\
\hline Alimentary tract hemorrhage & $3(1.41)$ & $30.61(29.42-31.65)$ & $3.30(3.12-3.47)$ & $\begin{array}{l}\text { The drug dosage was reduced } \\
\text { according to the patient's condition }\end{array}$ \\
\hline Nasal hemorrhage & $8(3.76)$ & $27.63(26.76-28.44)$ & $3.01(2.69-3.30)$ & $\begin{array}{l}\text { Drug dose was reduced according } \\
\text { to the patient's condition }\end{array}$ \\
\hline Hematuresis & $3(1.41)$ & $29.25(28.37-30.12)$ & $3.63(3.54-3.71)$ & $\begin{array}{l}\text { The drug dosage was reduced } \\
\text { according to the patient's condition }\end{array}$ \\
\hline Gingival bleeding & $7(3.29)$ & $27.23(25.03-29.43)$ & $2.90(2.71-3.12)$ & $\begin{array}{l}\text { Drug dose was reduced according } \\
\text { to the patient's condition }\end{array}$ \\
\hline
\end{tabular}

Values are expressed as n (\%) or median (range). PT, prothrombin time; INR, international normalized ratio.

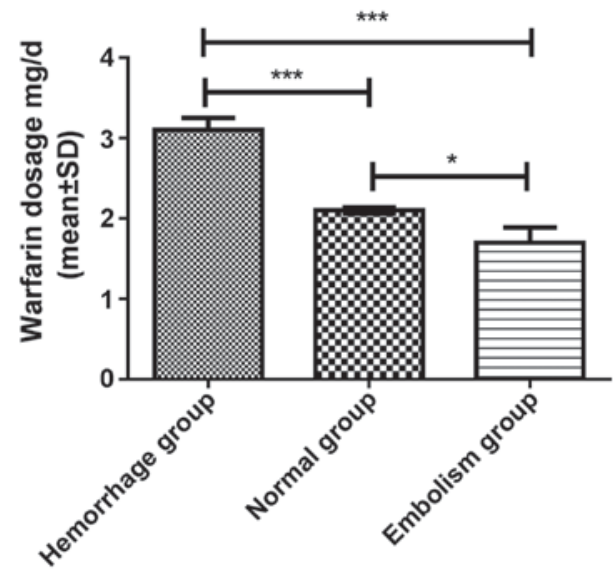

Figure 1. Warfarin dosage in the patients grouped based on adverse events. ${ }^{*} \mathrm{P}<0.05,{ }^{* * *} \mathrm{P}<0.001$.

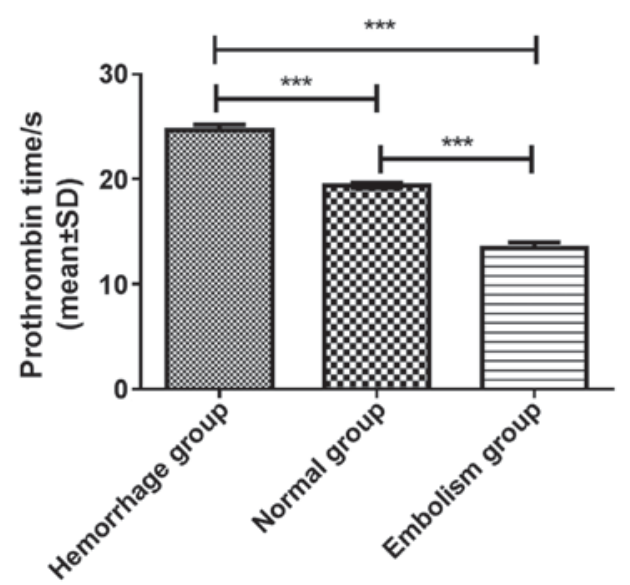

Figure 2. Prothrombin time in the patients grouped based on adverse events. ${ }^{* * * *} \mathrm{P}<0.001$

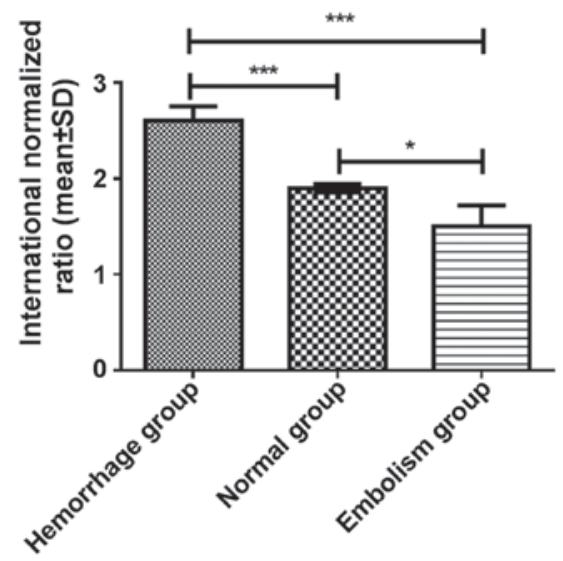

Figure 3. International normalized ratio in the patients grouped based on adverse events. ${ }^{*} \mathrm{P}<0.05,{ }^{* * * *} \mathrm{P}<0.001$.

range of INR after cardiac valve replacement. It has been reported that the coagulation function in the Japanese population is lower than that in western countries, and Japanese patients are more likely to have hemorrhage symptoms (20). The PT and INR analyses performed on 213 patients using warfarin found that the PT $(19.4 \pm 3.1 \mathrm{sec})$ and the INR $(1.9 \pm 0.6)$ in the normal group were basically consistent with those reported in domestic studies (21-23). In recent years, an increasing number of anti-coagulant drugs have been gradually promoted, which have a fast onset and long-lasting effect compared with that of warfarin. However, the time to market for such drugs is relatively short, their price is relatively high compared with that of warfarin, and large-scale controlled trials to verify their efficacy and safety are currently lacking. Therefore, the safety and applicability of these drugs requires further confirmation (24-26). 
Of note, the present study had certain shortcomings, including the small number of subjects. This may be the reason for the larger INR standard deviations. Secondly, the ideal range of INR was not predicted. Therefore, the number of samples will be increased and an ideal INR range may be determined in future studies, so as to verify the results of the current study.

In conclusion, INR-guided warfarin anti-coagulation treatment is recommended to ensure the safety of elderly patients after cardiac valve replacement, but a reasonable target range of the INR still requires further investigation.

\section{Acknowledgements}

Not applicable.

\section{Funding}

No funding was received.

\section{Availability of data and materials}

The analyzed data sets generated during the study are available from the corresponding author on reasonable request.

\section{Authors' contributions}

JHF contributed to the conception of the current study, performed the experimental studies and data analysis, acquired the data, and edited and reviewed the manuscript. QHM contributed to study design, statistical analysis, literature research, clinical studies and manuscript preparation. The final version of the manuscript has been read and approved by the two authors and each author believes that the manuscript represents honest work.

\section{Ethical approval and consent to participate}

The present study was approved by the Medical Ethics Committee of Linyi Central Hospital (Linyi, China), and the spouses/guardians of all patients provided written informed consent.

\section{Patient consent for publication}

Not applicable.

\section{Competing interests}

The authors declare that they have no competing interests.

\section{References}

1. Coffey S, Harper AR, Cairns BJ, Roberts IS and Prendergast BD: Clinical information has low sensitivity for postmortem diagnosis of heart valve disease. Heart 103: 1031-1035, 2017.

2. Chambers JB, Prendergast B, Iung B, Rosenhek R, Zamorano JL, Piérard LA, Modine T, Falk V, Kappetein AP, Pibarot P, et al: Standards defining a 'Heart Valve Centre': ESC Working Group on Valvular Heart Disease and European Association for Cardiothoracic Surgery Viewpoint. Eur Heart J 38: 2177-2183, 2017.
3. Schaefer A, Sill B, Schoenebeck J, Schneeberger Y, Reichenspurner $\mathrm{H}$ and Gulbins H: Failing stentless Bioprostheses in patients with carcinoid heart valve disease. J Cardiothorac Surg 10: 41, 2015.

4. Duffy N, Xue YQ and Hughes L: Prosthetic heart valve devices and methods of valve repair. US Patent US9795482B2. Filed April 27, 2010; issued October 24, 2017.

5. Chikwe J, Chiang YP, Egorova NN, Itagaki S and Adams DH: Survival and outcomes following bioprosthetic vs mechanical mitral valve replacement in patients aged 50 to 69 years. JAMA 313: 1435-1442, 2015.

6. Spenser B, Benichou N, Bash A and Zakai A: Prosthetic heart valve and method. US Patent US 20170224481 A1. Filed April 24, 2017; issued August 10, 2017.

7. Eikelboom JW, Connolly SJ, Brueckmann M, Granger CB, Kappetein AP, Mack MJ, Blatchford J, Devenny K, Friedman J, Guiver K, et al: Dabigatran versus warfarin in patients with mechanical heart valves. N Engl J Med 369: 1206-1214, 2013.

8. Schwann TA, Habib RH, Suri RM, Brennan JM, He X, Thourani VH, Engoren M, Ailawadi G, Englum BR, Bonnell MR and Gammie JS: Variation in warfarin use at hospital discharge after isolated bioprosthetic mitral valve replacement: An analysis of the society of thoracic surgeons adult cardiac surgery database. Chest 150: 597-605, 2016.

9. Gudmundsdottir BR, Jonsson PI and Onundarson PT: INR and vitamin K: Dependent coagulation factor fluctuation during warfarin initiation and stable therapy in patients dosed with the fiix-prothrombin time or the quick prothrombin time. The Fiix Trial. Blood 124: 4278, 2014.

10. Qian X: Influence of pharmacist intervention on the knowledge of anticoagulation therapy with warfarin by the patient. Pharmacotherapy 35, 2015.

11. Nakano T, Nakamura T, Nakamura Y, Irie K, Sato K, Matsuo K, Imakyure O, Ogata K, Mishima K and Kamimura H: Effects of Teicoplanin on the PT-INR controlled by warfarin in infection patients. Yakugaku Zasshi 137: 909-916, 2017 (In Japanese).

12. Yang X, Li Z, Zhao X, Wang C, Liu L, Wang C, Pan Y, Li H, Wang D, Hart RG, et al: Use of warfarin at discharge among acute ischemic stroke patients with nonvalvular atrial fibrillation in China. Stroke 47: 464-470, 2016.

13. Dong L, Shi YK, Xu JP, Zhang EY, Liu JC, Li YX, Ni YM, Yang Q, Han T, Fu B, et al: The multicenter study on the registration and follow-up of low anticoagulation therapy for the heart valve operation in China. Zhonghua Yi Xue Za Zhi 96: 1489-1494, 2016 (In Chinese).

14. Parks T, Mirabel MM, Kado J, Auckland K, Nowak J, Rautanen A, Mentzer AJ, Marijon E, Jouven X, Perman ML, et al: Association between a common immunoglobulin heavy chain allele and rheumatic heart disease risk in Oceania. Nat Commun 8: 14946, 2017.

15. Zuhlke L, Engel ME, Karthikeyan G, Rangarajan S, Mackie P, Cupido B, Mauff K, Islam S, Joachim A, Daniels R, et al: Characteristics, complications, and gaps in evidence-based interventions in rheumatic heart disease: The Global Rheumatic Heart Disease Registry (the REMEDY study). Eur Heart J 36: 1115-1122a, 2015.

16. Matchar DB, Love SR, Jacobson AK, Edson R, Uyeda L, Phibbs CS and Dolor RJ: The impact of frequency of patient self-testing of prothrombin time on time in target range within VA Cooperative Study \#481: The Home INR Study (THINRS), a randomized, controlled trial. J Thromb Thrombolysis 40: 17-25, 2015.

17. Mcdowell TY, Lawrence J, Florian J, Southworth MR, Grant S and Stockbridge N: Relationship between International normalized ratio and outcomes in modern trials with warfarin controls. Pharmacotherapy 38: 899-906, 2018.

18. Van de Werf F, Brueckmann M, Connolly SJ, Friedman J, Granger CB, Härtter S, Harper R, Kappetein AP, Lehr T, Mack MJ, et al: A comparison of dabigatran etexilate with warfarin in patients with mechanical heart valves: THE Randomized, phase II study to evaluate the safety and pharmacokinetics of oral dabigatran etexilate in patients after heart valve replacement (RE-ALIGN). Am Heart J 163: 931-937.e1, 2012.

19. Jiang X, Huang $X$ and Bao J: Application and discussion of health education in Warfarin therapy of atrial fibrillation patients. China Med Herald (Zhong Guo Yi Yao Dao Bao) 5: 099, 2011 (In Chinese).

20. Liu Y, Yu XY,Zhong SL, Yang M, Tan HH, Fei HW and Chen JY: Clinical application of anticoagulation treatment with warfarin after prosthetic heart valve replacement: A single center-based survey. Nan Fang Yi Ke Da Xue Xue Bao 30: 2242-2245, 2010 (In Chinese). 
21. Go AS, Singer DE, Toh S, Cheetham TC, Reichman ME, Graham DJ, Southworth MR, Zhang R, Izem R, Goulding MR, et al: Outcomes of Dabigatran and warfarin for atrial fibrillation in contemporary practice: A retrospective cohort study. Ann Intern Med 167: 845-854, 2017.

22. Fan Y, Dong L, Zhang D, Xiang D and Li Y: Correlation between demographic factors and warfarin stable dosage in population of Western China. Biomed Res 28: 8249-8253, 2017.

23. Yu Z, Ding YL, Lu F, Miao LY, Shen ZY and Ye WX: Warfarin dosage adjustment strategy in Chinese population. Int J Clin Exp Med 8: 9904-9910, 2015

24. You JH, Chan FW, Wong RS and Cheng G: Is INR between 2.0 and 3.0 the optimal level for Chinese patients on warfarin therapy for moderate-intensity anticoagulation? Br J Clin Pharmacol 59: $582-587,2005$
25. Volpp KG, Loewenstein G, Troxel AB, Doshi J, Price M, Laskin $M$ and Kimmel SE: A test of financial incentives to improve warfarin adherence. BMC Health Serv Res 8: 272, 2008.

26. Larsen TB, Rasmussen LH, Skjøth F, Due KM, Callréus T, Rosenzweig M and Lip GY: Efficacy and safety of dabigatran etexilate and warfarin in 'real-world' patients with atrial fibrillation: A prospective nationwide cohort study. J Am Coll Cardiol 61: 2264-2273, 2013. 